\title{
Determination of Nickel in Water Samples by Graphite Furnace Atomic Absorption Spectrometry After Ionic Liquid-Based Dispersive Liquid-Liquid Microextraction Preconcentration
}

\author{
Pei Liang* and Lili Peng \\ Key Laboratory of Pesticide \& Chemical Biology of Ministry of Education, College of Chemistry, \\ Central China Normal University, Wuhan 430079, P. R. China
}

\section{INTRODUCTION}

Nickel (Ni) is an important element and widely used in the manufacture of alloys due to its high strength, high melting point $\left(1453^{\circ} \mathrm{C}\right)$, and resistance to corrosion in many media (1). Nickel enters aquatic systems through anthropogenic activities, such as mining, smelting, refining, alloy production, plating, fuel combustion, waste incineration, or through the discharge of effluents bearing nickel. Nickel, even at low concentrations, has severe short- and longterm effects on the health of individuals, is carcinogenic, and causes atopic dermatitis $(2,3)$. The primary route for nickel toxicity is mainly due to inhalation and contaminated food and water. Thus, it is very important to determine the nickel content in food and water samples (4).

The direct determination of trace nickel in environmental samples is usually difficult particularly due to its low concentration and matrix effects. Although the graphite furnace atomic absorption spectrometric (GFAAS) method is a powerful analytical tool for the determination of trace elements in environmental samples, an initial sample pretreatment is still necessary. The widely used techniques for the separation and preconcentration of nickel include liquid-liquid extraction $(5,6)$, coprecipitation $(7,8)$, solid-phase extraction (9-12), and cloud point extraction $(13,14)$,

*Corressponding author

E-mail: liangpei@mail.ccnu.edu.cn

\section{ABSTRACT}

A novel method based on ionic liquid dispersive liquid-liquid microextraction (IL-DLLME) preconcentration and graphite furnace atomic absorption spectrometry detection was developed for the determination of nickel in lake water, tap water, and seawater samples. In the proposed method, 1-(2-pyridylazo)-2naphthol (PAN) was used as the chelating agent, acetone as the dispersive solvent, and ionic liquid (1-butyl-3-methylimidazolium hexafluorophosphate) as the extraction solvent instead of a volatile organic solvent. Some parameters influencing the ILDLLME extraction efficiency of nickel and its subsequent determination, such as the type and volume of IL and dispersive solvent, $\mathrm{pH}$, the amount of PAN, extraction time and centrifuge time, were investigated.

Under the optimum conditions, the enrichment factor was 67, the detection limit for nickel was $18 \mathrm{ng} \mathrm{L}^{-1}(3 \sigma)$, and the relative standard deviation (RSD) was $6.5 \%\left(\mathrm{n}=7, \mathrm{c}=5.0 \mathrm{ng} \mathrm{mL}^{-1}\right)$. The method was successfully applied to the determination of trace amounts of nickel in different water samples.

but they are time-consuming, require large organic solvents, and result in unsatisfactory enrichment factors and secondary waste.

Dispersive liquid-liquid microextraction (DLLME) is a novel microextraction technique, which is based on a ternary component sol- vent system like homogeneous liquid-liquid extraction and cloud point extraction (15). It is simple, rapid, and low cost, uses low sample volume, and offers high recovery and a high enrichment factor. DLLME has been widely used for the extraction of organic compounds and metal ions in environmental samples (16-19). However, the extraction and dispersive solvents used in DLLME are still volatile organic compounds.

Ionic liquids (ILs) are considered green solvents and are of interest due to their promising role as alternative solvents in organic synthesis, catalysis, electrochemistry, etc. (20, 21). ILs have negligible vapor pressure and non-flammability, as well as good solubility for inorganic and organic compounds, and have been successfully applied in various areas of analytical chemistry, especially in separation sciences (22-25). Many liquid-phase microextraction (LPME) methods based on ILs have been developed for the determination of organic compounds and metal ions (26-30). Ionic liquidbased DLLME (IL-DLLME) has also been applied to the extraction of different organic compounds and shows some advantages over conventional extraction techniques, such as fast and easy operation, and does not require highly toxic chlorinated solvents (31-33). However, there are few reports available on the application of IL-DLLME for the preconcentration of metal ions (34-36).

The aim of this work was to assess the IL-DLLME technique combined with graphite furnace 
atomic absorption spectrometry (GFAAS) for the determination of nickel in real water samples. The chelating reagent 1-(2-pyridylazo)-2naphthol (PAN) was used, which reacts with metallic ions and forms a very stable complex, and has been applied to numerous applications in trace element separation and preconcentration $(37,38)$. The factors influencing IL-DLLME preconcentration and GFAAS determination were systematically studied.

\section{EXPERIMENTAL}

\section{Instrumentation}

A TBS-990 atomic absorption spectrophotometer (Beijing Purkinge General Instrument Co., Ltd., Beijing, P.R. China), equipped tion and a GF990 graphite furnace atomizer system, was used. A nickel hollow cathode lamp was used as the radiation source at $232.0 \mathrm{~nm}$. The optimum operating parameters for GFAAS are given in Table I. The $\mathrm{pH}$ values were measured with a Mettler Toledo 320-S pH meter (Mettler Toledo Instruments Co., Ltd., Shanghai, P.R. China). An 80-2 centrifuge (Changzhou Guohua Electric Appliance Co., Ltd., P.R. China) was used to accelerate phase separation. A MK-III microwave digestion system (Shinco Institute of Microwave Digestion Technolwith deuterium background correc-

ogy, Shanghai, P.R. China) was used to dissolve the samples.

\section{Standard Solutions and Reagents}

The stock standard solution (1000 $\mathrm{mg} \mathrm{L}^{-1}$ ) of Ni was obtained from the National Institute of Standards (Beijing, P.R. China). Working standard solutions were obtained by appropriate dilution of the stock standard solution. The solution of PAN was prepared by dissolving appropriate amounts of PAN (AR, Shanghai Chemistry Reagent Company, Shanghai, P.R. China) in ethanol. Extraction solvents of 1-butyl-3-methylimidazolium hexafluorophosphate $\left(\left[\mathrm{C}_{4} \mathrm{MIM}\right]\left[\mathrm{PF}_{6}\right]\right)$ and 1-octyl-3methylimidazolium hexafluorophosphate ( $\left.\left[\mathrm{C}_{8} \mathrm{MIM}\right]\left[\mathrm{PF}_{6}\right]\right)$ were purchased from Shanghai Chengjie Chemical Co., Ltd. (Shanghai, P.R. China). A borate buffer solution $\left(0.01 \mathrm{~mol} \mathrm{~L}^{-1}\right)$ was prepared by dissolving appropriate amounts of boric acid in water and adjusting to pH 10.0 by adding diluted $\mathrm{NaOH}$ solution. All other reagents used were of the highest available purity and of at least analytical reagent grade. Doubly distilled water was used throughout. Pipettes and vessels used in the experiments were kept in $10 \%$ nitric acid for at least 24 hours and subsequently washed four times with doubly distilled water.

TABLE I

GFAAS Operating Parameters

\begin{tabular}{ll}
\hline Parameters & \\
\hline Lamp Current & $4.0 \mathrm{~mA}$ \\
Wavelength & $232.0 \mathrm{~nm}$ \\
Slit & $0.2 \mathrm{~nm}$ \\
Ar Flow Rate & $200 \mathrm{~mL} \mathrm{~min}-1$ (stopped during atomizing) \\
Sample Volume & $20 \mu \mathrm{L}$ \\
\hline Temperature Program & \\
\hline Drying & $120{ }^{\circ} \mathrm{C}(\operatorname{Ramp~} 15 \mathrm{~s}$, Hold $10 \mathrm{~s})$ \\
Ashing & $600{ }^{\circ} \mathrm{C}(\operatorname{Ramp~} 10 \mathrm{~s}$, Hold $10 \mathrm{~s})$ \\
Atomizing & $2000^{\circ} \mathrm{C}(\operatorname{Ramp~} 0 \mathrm{~s}$, Hold $3 \mathrm{~s})$ \\
Cleaning & $2200^{\circ} \mathrm{C}(\operatorname{Ramp~} 1 \mathrm{~s}$, Hold $3 \mathrm{~s})$ \\
\hline
\end{tabular}

Dispersive Liquid-liquid Microextraction Procedure

Aliquots of $5.0 \mathrm{~mL}$ sample solution containing $\mathrm{Ni}$ and $1.5 \times 10^{-5} \mathrm{~mol} \mathrm{~L}^{-1} \mathrm{PAN}$, the $\mathrm{pH}$ being maintained at 10.0 by a borate buffer, were placed in 10-mL screw cap glass test tubes with conic bottoms. $0.2 \mathrm{~mL}$ of acetone (dispersive solvent) containing $40 \mu \mathrm{L}$ of $\left[\mathrm{C}_{4} \mathrm{MIM}\right]\left[\mathrm{PF}_{6}\right]$ (extraction solvent) was injected rapidly into the sample solution with a $1.00 \mathrm{~mL}$ syringe. A cloudy solution was formed in the test tube. In this step, the complex of Ni with PAN was extracted into the fine ionic liquid droplets. Then, the mixture was centrifuged at $3000 \mathrm{rpm}$ for $14 \mathrm{~min}$ utes. After this process, the dispersed fine droplets of ionic liquid were deposited at the bottom of the conical test tubes (about $25 \mu \mathrm{L}$ ). Then, $20 \mu \mathrm{L}$ of the sediment phase was removed using a $50-\mu \mathrm{L}$ microsyringe (minimum scale of $1 \mu \mathrm{L}$ ) and injected into the GFAAS for analysis.

Calibration was performed against aqueous standards submitted to the same DLLME procedure. A blank submitted to the same procedure described above was measured parallel to the sample and calibration solutions.

\section{RESULTS AND DISCUSSION}

\section{Effect of Ionic Liquid and Its Volume}

The type of extraction solvent used in DLLME is an essential consideration for efficient extraction. It should be water-immiscible, liquid in the experimental conditions, have an extraction capability of the compounds of interest, and higher density than water. Imidazolium-ILs with $\mathrm{PF}_{6}{ }^{-}$as anion are hydrophobic and relatively inexpensive, and were used in this work. $\left[\mathrm{C}_{4} \mathrm{MIM}\right]\left[\mathrm{PF}_{6}\right]$ and $\left[\mathrm{C}_{8} \mathrm{MIM}\right]\left[\mathrm{PF}_{6}\right]$ were studied as extraction solvents using $0.2 \mathrm{~mL}$ of acetone as the dispersive 
solvent. It was found that a higher analytical signal of $\mathrm{Ni}$ was obtained when $\left[\mathrm{C}_{4} \mathrm{MIM}\right]\left[\mathrm{PF}_{6}\right]$ was used. Therefore, $\left[\mathrm{C}_{4} \mathrm{MIM}\right]\left[\mathrm{PF}_{6}\right]$ was selected as the extraction solvent in subsequent experiments.

In order to examine the effect of the volume of IL, solutions containing $0.2 \mathrm{~mL}$ of acetone and different amounts of IL in the range of 20-60 $\mu \mathrm{L}$ were subjected to the same DLLME procedure. It was found that the analytical signal of $\mathrm{Ni}$ increases in accordance with an increase in volume of IL up to $40 \mu \mathrm{L}$, then it starts to decrease. This dropoff may be due to a rise in sediment volume. Thus, $40 \mu \mathrm{L}$ of $\left[\mathrm{C}_{4} \mathrm{MIM}\right]\left[\mathrm{PF}_{6}\right]$ was used for subsequent experiments.

\section{Effect of Type and Volume of Dispersive Solvent}

For the DLLME method, the main criterion for the selection of dispersive solvent is its miscibility in the extraction solvent and aqueous solution. Therefore, acetone, acetonitrile, and methanol were tested as dispersive solvents. The effect of these solvents on the extraction efficiency of DLLME was investigated using $0.2 \mathrm{~mL}$ of each solvent containing $40 \mu \mathrm{L}$ of $\left[\mathrm{C}_{4} \mathrm{MIM}\right]\left[\mathrm{PF}_{6}\right]$ as the extraction solvent. The highest analytical signal of Ni was obtained with acetone as the dispersive solvent. So, acetone was selected as the dispersive solvent in this work.

The effect of the volume of acetone on the extraction efficiency was also examined. Various experiments were performed using different volumes of acetone $(0.10,0.20$, $0.30,0.40$, and $0.50 \mathrm{~mL}$ ) containing $30,40,45,50$, and $70 \mu \mathrm{L}$ of $\left[\mathrm{C}_{4} \mathrm{MIM}\right]\left[\mathrm{PF}_{6}\right]$, respectively. It was necessary to change the volume of IL by changing the volume of acetone to obtain a constant volume in the sediment phase $(25 \mu \mathrm{L})$. The results showed that the analytical signal of Ni increased with an increase in the volume of acetone up to $0.20 \mathrm{~mL}$. A reduction in the analytical signal was observed when the volume of acetone exceeded $0.20 \mathrm{~mL}$. Thus, $0.20 \mathrm{~mL}$ of acetone was used for subsequent experiments.

\section{Effect of pH}

Separation of the metal ions by DLLME involves prior complex formation with sufficient hydrophobic property in order to be extracted into the small volume of the IL phase, whereby the desired preconcentration is obtained. The $\mathrm{pH}$ of the sample solution plays a distinctive role in the formation of the complex and the subsequent extraction. The effect of $\mathrm{pH}$ on the DLLME extraction of $\mathrm{Ni}$ was studied in the $\mathrm{pH}$ range of 3 to 12 . As can be seen in Figure 1, the analytical signal of $\mathrm{Ni}$ increased with an increase in $\mathrm{pH}$ from 3.0 to 9.0, and then remained almost constant. In this work, a pH of 10.0 was selected as the compromise condition.

\section{Effect of PAN Concentration}

The influence of the concentration of PAN on the DLLME extraction of $\mathrm{Ni}$ was evaluated in the range of $5 \times 10^{-6}$ to $2.5 \times 10^{-5} \mathrm{~mol} \mathrm{~L}^{-1}$. As can be seen in Figure 2, the analytical signal of $\mathrm{Ni}$ increased with an increase in the concentration of PAN up to $1.5 \times 10^{-5} \mathrm{~mol} \mathrm{~L}^{-1}$ and then decreased. The decrease is

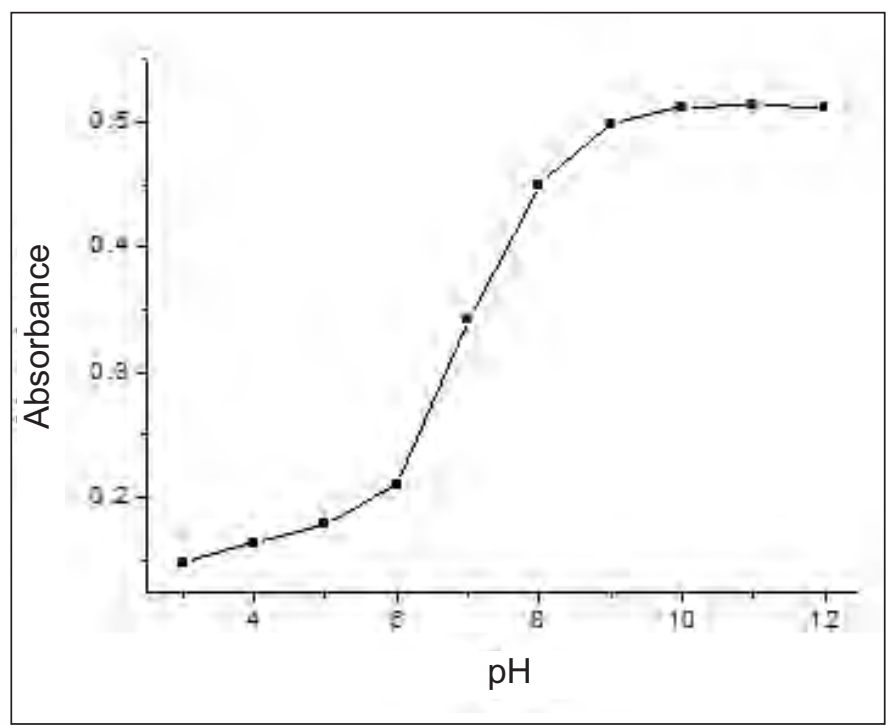

Fig. 1. Effect of $p H$ of the sample solution on the IL-DLLME extraction of Ni. IL-DLLME conditions: Ni, $5.0 \mu \mathrm{g} \mathrm{L}^{-1}$; sample volume, $5.0 \mathrm{~mL}$; dispersive solvent (acetone) volume, $0.2 \mathrm{~mL} ;\left[\mathrm{C}_{4} \mathrm{MIM}\right]\left[\mathrm{PF}_{6}\right]$ volume, $40 \mu \mathrm{L} ; \mathrm{PAN}$ concentration, $1.5 \times 10^{-5} \mathrm{~mol} \mathrm{~L}^{-1}$.

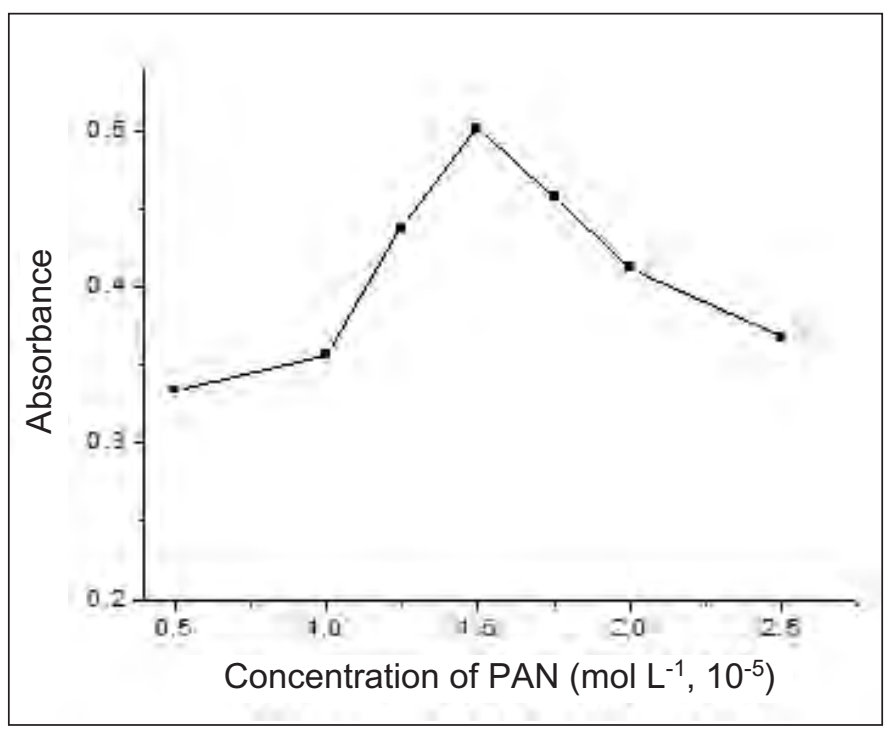

Fig. 2 Effect of PAN concentration on the IL-DLLME extraction of Ni. IL-DLLME conditions: $N i$, $5.0 \mu g L^{-1}$; sample volume, $5.0 \mathrm{~mL}$; dispersive solvent (acetone) volume, $0.2 \mathrm{~mL}$; $\left[C_{4} M I M\right]\left[P F_{6}\right]$ volume, $40 \mu \mathrm{L} ; \mathrm{pH} 10.0$. 
probably due to the competition of PAN itself with the Ni-PAN complex to be extracted into IL. Hence, a PAN concentration of $1.5 \times 10^{-5} \mathrm{~mol} \mathrm{~L}^{-1}$ was employed in this study.

\section{Effect of Extraction Time}

IL-DLLME involves a transfer of analyte from the aqueous phase into the ionic liquid phase which is time-dependent. The extraction time in this experiment was defined as the interval between injection of the mixture of acetone and ionic liquid and the start of centrifugation. The effect of extraction time was investigated within the range of 5 to 20 minutes using the experimental conditions described. As shown in Figure 3, the absorbance-time curve revealed that the extraction equilibrium could be attained within 16 minutes, a longer extraction time did not affect the extraction efficiency by much. Hence, the cloudy solution was left standing for $16 \mathrm{~min}$ utes before centrifugation.

\section{Effect of Centrifugation Time}

Centrifugation is an important step in order to obtain two distinguishable phases in the method. After a certain centrifugation time, the IL phase can be separated from the aqueous phase very well. In order to achieve the best extraction efficiency, a centrifugation time in the range of 3 to 20 minutes was considered. It was found that the highest analytical signal of $\mathrm{Ni}$ was obtained with a centrifugation time of 14 minutes. When the centrifugation time was longer or shorter than 14 minutes, the analytical signal decreased. Maybe a shorter centrifugation time resulted in the incomplete sedimentation of the IL drops and a longer centrifugation time resulted in heat generation, which led to dissolving parts of the IL phase. Therefore, the time of 14 minutes was adopted in further studies.

\section{Pyrolysis and Atomization Curves}

The purpose of the pyrolysis step prior to atomization is to remove the matrix as much as possible in order to reduce the magnitude of the background signal. In order to avoid Ni loss during the pyrolysis step, the optimal pyrolysis temperature should be selected. Pyrolysis and atomization curves were established using $5.0 \mu \mathrm{g} \mathrm{L}^{-1}$ of Ni solution submitted to the ILDLLME procedure. Figure 4 shows that the optimum pyrolysis and atomization temperatures for $\mathrm{Ni}$ were $600{ }^{\circ} \mathrm{C}$ and $2000^{\circ} \mathrm{C}$, respectively.

\section{Interferences}

The potential interference in the present method was investigated. The interference was due to the competition of other metal ions for the chelating agent and their subsequent co-extraction with $\mathrm{Ni}$. In these experiments, solutions containing $5.0 \mu \mathrm{g} \mathrm{L}^{-1}$ of $\mathrm{Ni}$ and the interfering ions were treated according to the recommended

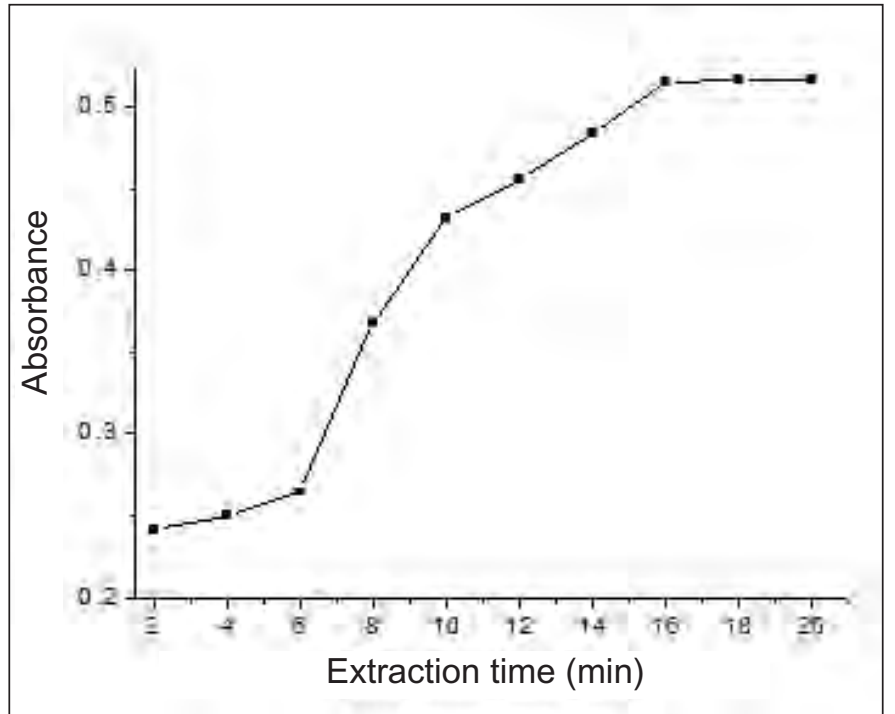

Fig. 3. Effect of extraction time on the IL-DLLME extraction of Ni. IL-DLLME conditions: $N i$, $5.0 \mu g L^{-1}$; sample volume, $5.0 \mathrm{~mL}$; dispersive solvent (acetone) volume, $0.2 \mathrm{~mL}$; $\left[\mathrm{C}_{4} \mathrm{MIM}\right]\left[\mathrm{PF}_{6}\right]$ volume, $40 \mu \mathrm{L} ; \mathrm{PAN}$ concentration, $1.5 \times 10^{-5} \mathrm{~mol} \mathrm{~L}^{-1}, \mathrm{pH} 10.0$.

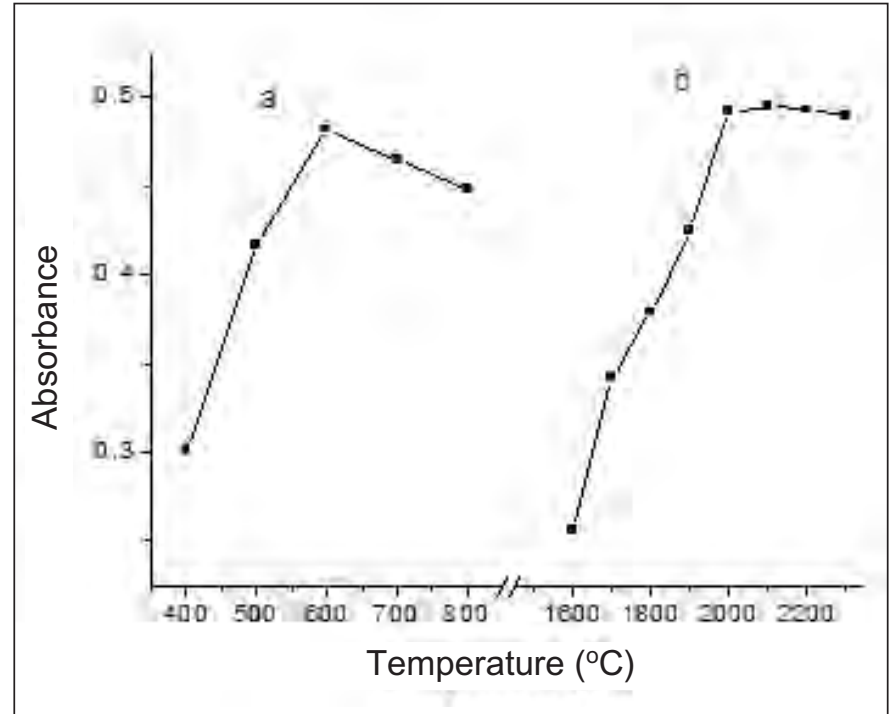

Fig. 4. Pyrolysis curve (a) and atomization curve (b) for $\mathrm{Ni}$ after IL-DLLME extraction. IL-DLLME conditions: $N i$, $5.0 \mu \mathrm{g} \mathrm{L}^{-1}$; sample volume, $5.0 \mathrm{~mL}$; dispersive solvent (acetone) volume, $0.2 \mathrm{~mL}$; [C $\left.\mathrm{C}_{4} \mathrm{MIM}\right]\left[\mathrm{PF}_{6}\right]$ volume, $40 \mu \mathrm{L} ; \mathrm{PAN}$ concentration, $1.5 \times 10^{-5} \mathrm{~mol} \mathrm{~L}^{-1}, \mathrm{pH} 10.0$. 
procedure. The tolerance limits of the coexisting ions, defined as the largest amount making the recovery of $\mathrm{Ni}$ less than $90 \%$, are listed in Table II. Large amounts of alkaline and alkaline earth metal ions have no interference on the DLLME extraction of $\mathrm{Ni}$ because of their very low stability constants of the PAN complexes.

\section{Evaluation of Method Performance}

For the purpose of quantitative analysis, a calibration curve for $\mathrm{Ni}$ with concentrations ranging over four orders was obtained by spiking the standards directly into doubly distilled water and extracting under the optimal conditions. Linearity was observed over the range of 0.5-100 $\mathrm{g} \mathrm{L} \mathrm{L}^{-1}$ with a correlation coefficient of 0.9972 . The limit of detection (LOD), based on a signalto-noise ratio $(\mathrm{S} / \mathrm{N})$ of 3 , was $18 \mathrm{ng} \mathrm{L}^{-1}$. The precision of this method was determined by analyzing the standard solution at $5.0 \mu \mathrm{g} \mathrm{L}^{-1}$ of $\mathrm{Ni}$ seven times continuously, and the relative standard deviation (RSD) obtained was $6.5 \%$. The enrichment factor, calculated as the ratio of the analytical signal of Ni obtained after and before extraction, was 67 for a 5.0-mL sample solution.

\section{Analysis of Real Samples}

The accuracy of the proposed method was examined by determin-

TABLE II

Tolerance Limits of Coexisting Ions

\begin{tabular}{lc}
\hline Coexisting Ions & $\begin{array}{c}\text { Tolerance } \\
\text { Limits }\left(\mathrm{mg} \mathrm{L}^{-1}\right)^{\mathrm{a}}\end{array}$ \\
\hline $\mathrm{K}^{+}, \mathrm{Na}^{+}$ & 1000 \\
$\mathrm{Ca}^{2+}, \mathrm{Mg}^{2+}$ & 800 \\
$\mathrm{Al}^{3+}, \mathrm{Pb}^{+}$ & 5 \\
$\mathrm{Cd}^{2+}, \mathrm{Mn}^{2+}, \mathrm{Cr}^{3+}, \mathrm{Fe}^{3+}$ & 1 \\
$\mathrm{Cu}^{2+}, \mathrm{Co}^{2+}, \mathrm{Zn}^{2+}$ & 0.5 \\
$\mathrm{SO}_{4}{ }^{2-}, \mathrm{NO}_{3}{ }^{-}, \mathrm{Cl}^{-}$ & 1000 \\
\hline
\end{tabular}

${ }^{\mathrm{a}} \mathrm{Ni}^{2+}$ concentration $5.0 \mu \mathrm{g} \mathrm{L}^{-1}$. ing the concentration of $\mathrm{Ni}$ in environmental water reference material (ERMs, GSBZ 50009-88, P.R. China). The concentration of the coexisting ions in the reference material is $0.15 \mu \mathrm{g} \mathrm{mL}^{-1}$ of $\mathrm{Cd}, 1.51 \mu \mathrm{g} \mathrm{mL}^{-1}$ of $\mathrm{Cr}, 1.69 \mu \mathrm{g} \mathrm{mL}^{-1}$ of $\mathrm{Cu}, 1.68 \mu \mathrm{g} \mathrm{mL}^{-1}$ of $\mathrm{Pb}$, and $0.494 \mu \mathrm{g} \mathrm{mL}^{-1}$ of $\mathrm{Zn}$. The analytical value $\left(0.53 \pm 0.06 \mu \mathrm{g} \mathrm{mL}^{-1}\right.$, $\mathrm{n}=5$ ) was in good agreement with the certified value $\left(0.50 \pm 0.02 \mu \mathrm{g} \mathrm{mL}^{-1}\right)$.

The proposed method was also applied to the determination of $\mathrm{Ni}$ in lake water, tap water, and seawater samples. Lake water samples were collected from East Lake (Wuhan, P.R. China) and tap water samples were freshly collected in our laboratory after allowing the water to flow for 5 minutes. Seawater samples were collected from Xiamen, P.R. China. All water samples were filtered through a $0.45 \mu \mathrm{m}$ membrane filter and analyzed as quickly as possible after sampling. In addition, the recovery experiments of different amounts of $\mathrm{Ni}$ were carried out and the standard solution of $\mathrm{Ni}$ was added before preconcentration. The results in Table III show that the recoveries were reasonable for trace analysis and ranged from of $92-101 \%$.

TABLE III

Determination of $\mathrm{Ni}\left(\mu \mathrm{g} \mathrm{L}^{-1}\right)$ in Natural Water Samples $(\mathbf{n}=5)$

\begin{tabular}{lllr}
\hline Samples & Added & Found & $\begin{array}{r}\text { Rec. }^{2} \\
(\%)\end{array}$ \\
\hline Lake Water & 0 & $11.1 \pm 0.6$ & - \\
& 10 & $20.7 \pm 1.2$ & 96 \\
& 20 & $30.9 \pm 2.1$ & 99 \\
Tap Water & 0 & $4.5 \pm 0.3$ & - \\
& 10 & $14.3 \pm 0.8$ & 98 \\
& 20 & $24.7 \pm 1.5$ & 101 \\
Seawater & 0 & $8.8 \pm 0.6$ & - \\
& 10 & $18.3 \pm 1.1$ & 95 \\
& 20 & $27.2 \pm 1.6$ & 92 \\
\hline
\end{tabular}

${ }^{\mathrm{a}}$ Rec. $=$ Recovery .

\section{CONCLUSION}

In this work, a new method of dispersive liquid-liquid microextraction (DLLME), based on the use of ionic liquid (IL), was developed for the preconcentration of nickel in water samples (lake water, tap water, and seawater) prior to its determination by graphite furnace atomic absorption spectrometry (GFAAS). The use of a nonvolatile ionic liquid as the extraction solvent decreases the possibility of exposing the operator to a toxic solvent. IL-DLLME proved to be a rapid, simple, sensitive method offering a low limit of detection (18 $\mathrm{ng} \mathrm{L}^{-1}$ ) and a good enrichment factor (67). The proposed method can be applied to the determination of trace nickel in various water samples.

Received September 19, 2011.

\section{REFERENCES}

1. C. Ramachandraiah, J.R. Kumar, K.J. Reddy, S.L. Narayana and A.V. Reddy, J. Environ. Manage. 88, 729 (2008).

2. G. Scansetti, G. Maina, G.C. Botta, P Bambace and P. Spinelli, Environ. Health. 71, 60 (1998).

3. G.D. Nielsen, U. Soderberg, P.J. Jorgensen, D.M. Templeton, S.N. Rasmussen, K.E. Andersen and P. Grandjean, Toxicol. Appl. Pharm. 154, 67 (1999).

4. M.C. Yebra, S. Cancela and R.M. Cespon, Food Chem. 108, 774 (2008).

5. S. Ichinoki, C. Onishi and Y. Fujii, J. Liq. Chromatogr. R T 29, 2217 (2006).

6. L. Pan, Y.C. Qin, B. Hu and Z.C. Jiang, Chem. Res. Chinese Univ. 23, 399 (2007).

7. H.W. Chen, J.C. Jin and Y.F. Wang, Anal. Chim. Acta 353, 181 (1997).

8. M. Tuzen and M. Soylak, J. Hazard. Mater. 162, 724 (2009). 
9. J.H. Wang and E.H. Hansen, Anal. Chim. Acta 424, 223 (2000).

10. S.Z. Chen, M.F. Xiao, D.B. Lu and Z. Wang, Spectrochim. Acta Part B 62, 1216 (2007).

11. Q.X. Zhou, X.N. Zhao and J.P. Xiao, Talanta 77, 1774 (2009).

12. M. Karve and R.V. Rajgor, J. Hazard. Mater. 166, 576 (2009).

13. Z.M. Sun, P. Liang, Q. Ding and J. Cao, J. Hazard. Mater. 137, 943 (2006).

14. N. Shokoufi, F. Shemirani and F. Memarzadeh, Anal. Chim. Acta 601, 204 (2007).

15. M. Rezaee, Y. Assadi, M.R.M. Hosseini, E. Aghaee, F. Ahmadi and S. Berijani, J. Chromatogr. A 1116, 1 (2006).

16. L.J. He, C.J. Wang, Y.J. Sun, X.L. Luo, J. Zhang and K. Lu, Intern. J. Environ. Anal. Chem. 89, 439 (2009).

17. P. Hashemia, S. Beyranvanda, R.S. Mansurb and A.R. Ghiasvand, Anal. Chim. Acta 655, 60 (2009).

18. H.M. Jiang, Y.C. Qin and B. Hu, Talanta 74, 1160 (2008).

19. P. Liang, E.H. Zhao and F. Li, Talanta 77, 1854 (2009).

20. T. Welton, Chem. Rev. 99, 2071 (1999).

21. M.J. Earle and K.R. Seddon, Pure Appl. Chem. 72, 1391 (2000).

22. S. Pandey, Anal. Chim. Acta 556, 38 (2006)

23. J.L. Anderson, D.W. Armstrong and G.T. Wei, Anal. Chem. 77, 2893 (2006).

24. A. Berthod, M.J. Ruiz-Angel and S. Carda-Broch, J. Chromatogr. A 1184, 6 (2008).
25. R. Liu, J.F. Liu, Y.G. Yin, X.L. Hu and G.B. Jiang, Anal. Bioanal. Chem. 393, 871 (2009).

26. L.B, Xia, X. Li, Y.L. Wu, B. Hu and R. Chen, Spectrochim. Acta Part B 63, 1290 (2008).

27. M. Cruz-Vera, R. Lucena, S. Cardenas and M. Valcarcel, J. Chromatogr. A 1202, 1 (2008).

28. C. Basheer, Anass A. Alnedhary, B.S.M. Rao, R. Balasubramanian and H.K. Lee, J. Chromatogr. A 1210, 19 (2008).

29. F.Q. Zhao, S. Lu, W. Du and B.Z. Zeng, Microchim. Acta 165, 29 (2009).

30. J.L. Manzoori, M. Amjadi and J. Abulhassani, Anal. Chim. Acta 644, 48 (2009).

31. Y.C. Fan, Z.L. Hu, M.L. Chen, C.S. Tu and Y. Zhu, Chinese Chem. Letters, 19, 985 (2008).

32. Y. Liu, E.C. Zhao, W.T. Zhu, H.X. Gao and Z.Q. Zhou, J. Chromatogr. A 1216, 885 (2009).

33. Q.X. Zhou, X.G. Zhang and J.P. Xiao, J. Chromatogr. A 1216, 4361 (2009).

34. M. Gharehbaghi, F. Shemirani and M. Baghdadi, Intern. J. Environ. Anal. Chem. 89, 21 (2009).

35. M.H. Mallah, F. Shemirani and M.G. Maragheh, Environ. Sci. Technol. 43, 1947 (2009).

36. S.Q. Li, S. Cai, W. Hu, H. Chen and H.L. Liu, Spectrochim. Acta Part B 64, 666 (2009).

37. H. Filik, Z. Yanaz and R. Apak, Anal. Chim. Acta 620, 27 (2008).

38. X.S. Zhu, M. Wu and Y. Gu, Talanta 78, 565 (2009). 